\title{
HLA class I-drug-T-cell receptor interactions in SJS/TEN
}

\author{
Craig Rive ${ }^{1 *}$, Rebecca Pavlos ${ }^{1}$, David Ostrov², Pablo Plasencia ${ }^{2}$, Shien-lu Hung ${ }^{3}$, WenHung Chung ${ }^{4}$, Bjoern Peters ${ }^{5}$, \\ Soren Buus ${ }^{6}$, Simon Mallal ${ }^{7}$, Elizabeth Phillips ${ }^{7}$ \\ From 6th Drug Hypersensitivity Meeting (DHM 6) \\ Bern, Switzerland. 9-12 April 2014
}

\section{Background}

Carbamazepine (CBZ) is associated with the severe cutaneous drug reaction Stevens-Johnson Syndrome/toxic epidermal necrolysis (SJS/TEN). CBZ-SJS/TEN has been associated with HLA-B*15:02 carriage and specific T-cell clonotypes. We aimed to characterize the interactions between specific $\mathrm{T}$-cell receptor (TCR) clonotypes, HLA-B*15:02 and CBZ.

\section{Methods}

Peripheral blood mononuclear cells (PBMCs) were isolated from patients with CBZ-SJS/TEN and healthy controls, stimulated with $10 \mathrm{ug} / \mathrm{mL}$ CBZ (Sigma, cat. no. C4024-5G) and cultured over a 9-14 day period. RNA was isolated at various time points and TCR V subtypes were assessed using digital droplet PCR (Bio-Rad QX100 droplet digital PCR system). Drug specific T-cell INF and granulysin responses were assessed by ELISpot and ICS. In silico modelling was used to examine the interaction between the known specific TCR V and V chains, CBZ and HLA-B*15:02.

\section{Results}

CBZ specific T-cell INF and granulysin responses were detected many years following the original SJS/TEN reaction. Expansion of specific TCR CDR3 sequences was confirmed in CBZ SJS/TEN patient cultures. In silico modelling of the CBZ-HLA-B*15:02-TCR interaction suggests that $\mathrm{CBZ}$ binds non-covalently in the $\mathrm{P} 4$ binding pocket of the HLA-B*15:02 antigen binding cleft in a site that is typically occupied with bound peptide.

\section{Conclusions}

These findings raise two non-mutually exclusive possibilities: 1) CBZ may block peptide binding and be presented by HLA-B*15:02 in a solvent exposed manner available for direct recognition by the TCR, 2) CBZ binding the central portion of the HLA-B*15:02 antigen binding cleft may permit long peptides to bind conventionally at the peptide termini (in the A and F pockets) and bulge over the drug in the central residues to permit indirect recognition of CBZ (peptide mediated TCR contact).

\section{Authors' details \\ Institute for Immunology and Infectious Diseases, Murdoch University, Australia. ${ }^{2}$ University of Florida, College of Medicine, USA. ${ }^{3}$ Institute of Pharmacology, School of Medicine, Genome Research Centre, National Yang-Ming University, Taiwan. ${ }^{4}$ Department of Dermatology, Chang Gung Memorial Hospital, College of Medicine, Chang Gung University, Taiwan. ${ }^{5}$ La Jolla Institute for Allergy and Immunology, La Jolla, USA. 'aboratory of Experimental Immunology, University of Copenhagen, Denmark. ${ }^{7}$ Institute for Immunology and Infectious Diseases, Murdoch University, Murdoch WA, Australia, and Vanderbilt University Medical Centre, USA.}

Published: 18 July 2014

doi:10.1186/2045-7022-4-S3-P2

Cite this article as: Rive et al:: HLA class I-drug-T-cell receptor interactions in SJS/TEN. Clinical and Translational Allergy 2014 4(Suppl 3):P2

${ }^{1}$ Institute for Immunology and Infectious Diseases, Murdoch University,

Australia

Full list of author information is available at the end of the article

(c) 2014 Rive et al; licensee BioMed Central Ltd. This is an Open Access article distributed under the terms of the Creative Commons Attribution License (http://creativecommons.org/licenses/by/4.0), which permits unrestricted use, distribution, and reproduction in any medium, provided the original work is properly cited. The Creative Commons Public Domain Dedication waiver (http:// creativecommons.org/publicdomain/zero/1.0/) applies to the data made available in this article, unless otherwise stated. 